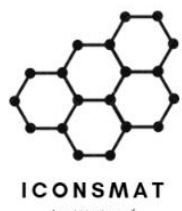

Institute of
Construction Materials
Int
Content list available at ICONSMAT

Journal of Construction Materials

Journal homepage: www.iconsmat.com.au/publication
Article history:

Received 9 January 2021

Received in revised form

4 February 2021

Accepted 11 February 2021

Available online

25 February 2021

\title{
Effect of temperature and salt on PVDF membrane wetting properties
}

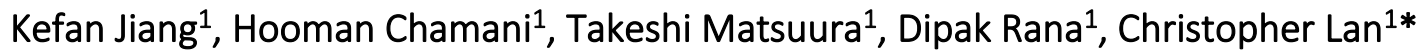 \\ ${ }^{1}$ Department of Chemical and Biological Engineering, University of Ottawa, 161 Louis Pasteur Private, \\ Ottawa, Ontario K1N 6N5, Canada \\ *Corresponding Author: Professor at Department of Chemical and Biological Engineering of the University of \\ Ottawa; E: clan@uottawa.ca
}

\begin{abstract}
Membrane distillation (MD) is a thermally driven separation process. Despite many advantages over other membrane separation processes, pore wetting hampers the wide commercial applications of the MD process. In this paper, the effect of temperature and presence (or absence) of salt in the feed solution on the wetting properties of commercial polyvinylidene fluoride (PVDF) membrane during a period of eight weeks was investigated. Liquid entry pressure (LEP) and water contact angle (WCA) were employed to characterize the wetting properties of the PVDF membrane. The result shows that the temperature has a significant impact on the decrease of the contact angle of the PVDF membrane.
\end{abstract}

DOI: 10.36756/JCM.si1.2 (C2021 Institute of Construction Materials

\section{(c) 9 (9)}

\section{Keywords:}

Membrane distillation; Wetting; Temperature; LEP; Contact angle. 


\section{Introduction}

Sustainable development has attracted attention in different fields, including $\mathrm{CO}_{2}$ capture, construction industry, petroleum engineering, etc. [1-4]. Desalination process should also be tackled from sustainability point of view. This process, i.e. desalination, is one of the most important methods to acquire the necessary freshwater for human life. Among the available desalination processes, membrane distillation (MD) process has drawn more attention recently as a promising technology [5]. In this process, a hydrophobic membrane is placed between salty feed solution and purified permeate water, and only water vapor is allowed to pass through the membrane pores, while non-volatile solutes such as electrolytes (salts) remain in the feed solution. Thus, near complete salt rejection is enabled. Unlike distillation process, the operating temperature required is lower than the boiling point of the feed solution and flexible. Also, unlike the pressure-driven membrane processes such as reverse osmosis (RO), no operating pressure is required for MD. In addition, the membrane pore size may not necessarily be as small as that of RO membrane [6]. Accordingly, MD process is operable at a mild condition, which allows the choice of more materials as well as equipment with less cost to be considered.

Despite all these advantages, MD has a serious disadvantage of membrane pore wetting. As mentioned, the MD membrane pores should be kept liquid-free, but during a long-term operation, the pores are gradually filled with liquid water, leading to the flux decrease and eventually making the salt rejection impossible.

There have been a number of reports on the MD process. Some of the examples are; on the solar energy utilization of MD [7], radioactive wastewater treatment [8], removal of heavy metals [9] and organic compounds [10] from the aqueous solutions.

MD process can be classified into four main categories [6], as shown in Fig. 1. Among those, direct contact membrane distillation (DCMD) (Fig. 1 (a)) is the simplest one. In this configuration, the membrane is in contact with the hot feed stream and the cold condensed stream and water is vaporized on the feed side. The vapor pressure of the hot liquid is higher than that of the cold liquid; thus, vapor flows through the pores from the hot liquid to the cold liquid side due to the vapor pressure gradient. The vapor is then condensed at the cold liquid side. In the meantime, the liquid (especially water) is prohibited from entering the pores due to the highly hydrophobic property of the membrane material. This is the most popular MD configuration because of its simplicity. However, there is a significant heat loss by the heat conduction through the membrane, which is the most serious disadvantage of this configuration [6].

Air gap membrane distillation (AGMD) (Fig. 1(b)) reduces the conduction heat loss of DCMD by introducing a stagnant air gap between the membrane and the cold condensed phase. However, it adds another resistance for vapor transport since the vapor should diffuse through the air gap [6].

In sweeping gas membrane distillation (SGMD) (Fig. 1(c)), sweep gas flows at the permeate side of the membrane carrying the vapor to an external condenser, where the condensation of the vapor takes place. SGMD can be combined with AGMD, where vapor condensation takes place partially at the cold condensation phase and partially at the external condenser. Thus, the construction of an external condenser with a large capacity is avoided. This combined method is also called thermostatic sweeping gas membrane distillation [11]. 
In vacuum membrane distillation (VMD) (Fig. 1 (d)), the conductive heat loss is almost negligible. A vacuum pump draws the vapor away from the membrane module into the external condenser [12].
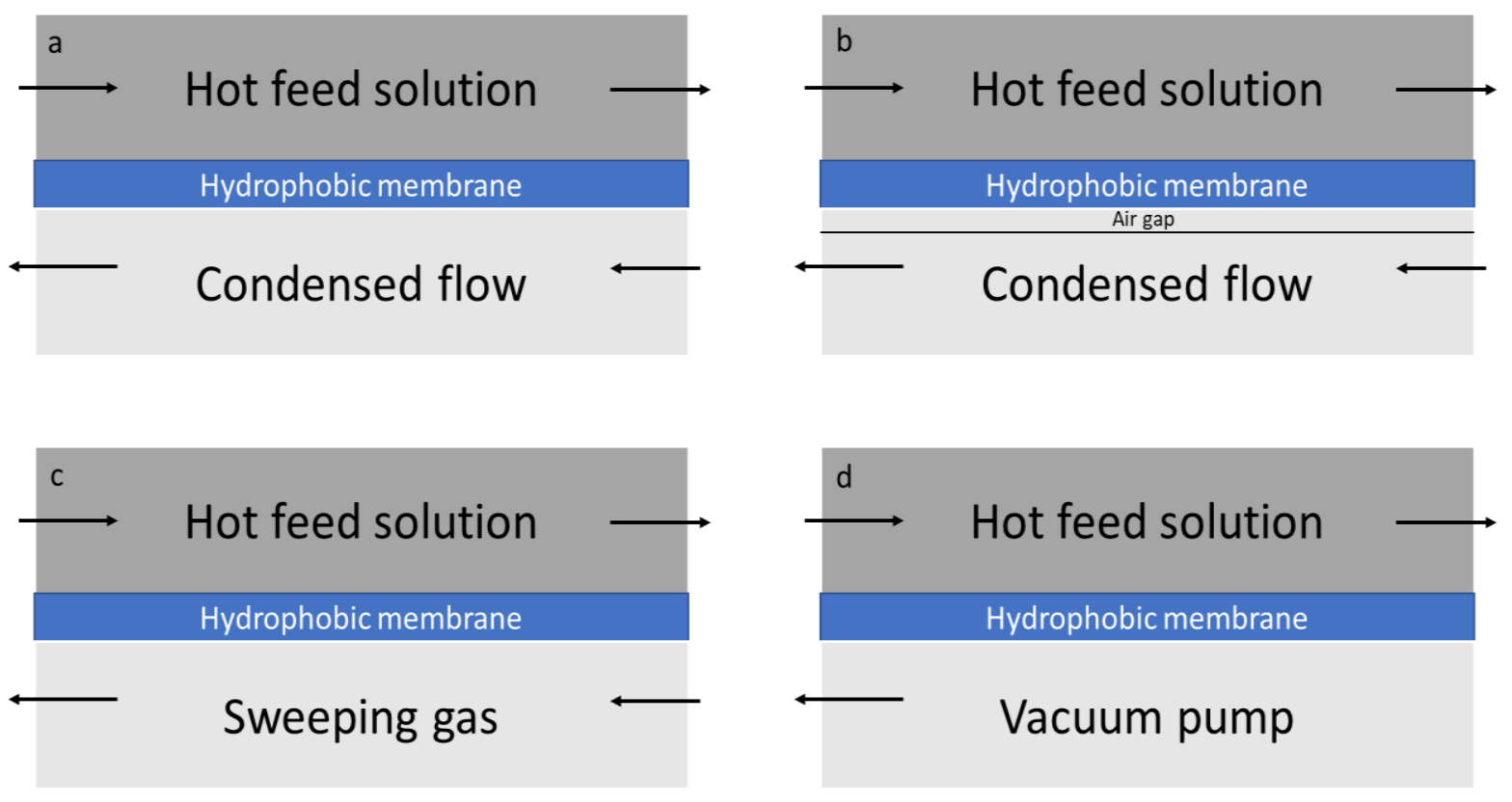

Fig. 1. Four types of MD process: (a) direct contact membrane distillation (DCMD), (b) air gap membrane distillation (AGMD), (c) sweeping gas membrane distillation (SGMD), and (d) vacuum membrane distillation (VMD).

As already mentioned, MD membrane materials should be hydrophobic. There are several well-known materials that can satisfy this requirement, including polytetrafluoroethylene (PTFE), polyvinylidene fluoride (PVDF) and polypropylene (PP). Hydrophilic materials whose surfaces are modified to hydrophobic can also be used for MD membranes [12].

The typical pore sizes of MD membranes are between $100 \mathrm{~nm}$ to $1 \mu \mathrm{m}$ [13] since there is a trade-off between permeate flux and liquid penetration. As pore size increases, the vapor flux increases, but the pressure at which liquid water penetrates into the membrane pore decreases, enhancing the chance of pore wetting, and vice versa. Therefore, the pore size should be optimized.

Membrane thickness is another significant parameter in MD process. The trade-off effect with permeate flux now changes from liquid penetration to heat transfer loss, which depends on the thermal conductivity of membrane material and that of the gas that fills the membrane pores. To reduce heat loss, thicker membranes with lower thermal conductivity are required. Thus, in DCMD process, membrane thickness is usually maintained in a range of 30-60 $\mu \mathrm{m}$ [14]. Design of composite membranes with a thin hydrophobic layer and a thick hydrophilic layer was proposed to increase the vapor flux while suppressing the heat loss. Also, it has been reported that an increase in membrane thickness reduces the average velocity of liquid/gas interface displacement inside the pore [15]. 
Membrane porosity is another parameter affecting MD performance. It is defined as the ratio of the volume occupied by the pores and the membrane itself. Membrane porosity $(\varepsilon)$ is hence calculated by the following equation [16]:

$\varepsilon=1-\frac{\rho_{\text {membrane }}}{\rho_{\text {polymer }}}$

where $\rho_{\text {membrane }}$ and $\rho_{\text {polymer }}$ are the density of the membrane and that of the polymeric material of which the membrane is made, respectively. It is also possible to measure the porosity of membrane using the drywet technique [17].

Tortuosity is a parameter that represents how much the pore structure is different from the straight cylindrical shape. High tortuosity leads to high resistance of vapor movement and low flux [6].

Liquid entry pressure (LEP) is a critical pressure at which liquid water starts to penetrate into the membrane pores. When LEP is high the membrane is less susceptible to pore wetting. LEP is dependent on the membrane pore size, membrane hydrophobicity, composition of feed solution and also membrane thickness [18,19]. One of the equations to calculate LEP is the following Franken's equation [12]:

$\Delta \mathrm{p}=\frac{-2 B \gamma_{L} \cos \theta}{r_{\max }}$

where $B$ is geometric factor related to the pore structure, $\nu_{L}$ is the surface tension of liquid, $\theta$ is the contact angle of liquid-solid surface and $r_{\max }$ is the maximum pore radius of the membrane. It is worth mentioning that surface tension is influenced by salt concentration [20]. Eykens et al. [21,22] suggested a threshold of 2.5 bar for LEP, meaning that the membranes having LEP $>2.5$ bar are appropriate for MD.

There are three states of wetting in the MD membrane [19]. First, pores of the membrane are filled with gas, which is called the non-wetted state. Second, some liquid enters the pores and pores are partially filled with liquid, which is called the transition state. Finally, liquid occupies the entire space of pores, which is called the wetted state.

With the changes of operational conditions like adding surfactants, increasing operation time, applying higher pressure (compared to the LEP), and so forth, the barrier for the liquid to enter pores is either reduced or overcome.

The electrical conductivity of the permeate will change when the feed solution of high salt content passes through the membrane, and this technique is widely used for the detection of pore wetting in the desalination process. Trying to detect pore wetting before contaminating the product stream, Chen et al. [19] developed a set of methods to measure the impedance of the membrane in advance, which suggests the wetting states indirectly. In addition to the leakage of feed to the permeate, pore wetting can decrease the permeate flux due to the decreased liquid temperature inside the pore [23].

As mentioned above, pore wetting is a serious drawback of MD, which should be investigated, prevented and detected carefully to avoid MD process failure. There are different parameters affecting pore wetting, one of which is the condition under which the MD process is operated. Particularly, temperature is an operational parameter for which conflicting experimental results have been reported in the literature. Guillen-Burrieza et al. [24] reported that an increase in feed temperature increased flux and delayed pore wetting. On the other hand, it has been suggested that a decrease in temperature increases surface tension resulting in delay in pore wetting [25]. Also, Saffarini et al. [26] investigated the effect of temperature on 
LEP (for PTFE membranes) and concluded that an increase in temperature negatively affected LEP. It is worth mentioning that the LEP measurement was carried out under high temperature conditions using a heater jacket in the LEP measurement setup.

The objective of this study is a long-term investigation of the effect of temperature and presence of salt on wetting characteristics of PVDF membrane in terms of water contact angle (WCA) and LEP. However, in contrast to Saffarini's research, the LEP measurements are performed at room temperature in order to exclude the effect of temperature on surface tension.

\section{Experimental procedure}

PVDF membranes with a nominal pore size of $0.1 \mu \mathrm{m}$, and thickness of $125 \mu \mathrm{m}$ were used. Sodium chloride $(\mathrm{NaCl})$ was purchased from Fisher Scientific, and deionized water was prepared using Quatra 90LC unit, Zenon Environmental Inc.

Membranes with a diameter of $47 \mathrm{~mm}$ (called coupons hereafter) were used. Membrane coupons were placed in a glass container of $2 \mathrm{~L}$, which was filled with either deionized water or artificial seawater prepared by dissolving $35 \mathrm{~g}$ of $\mathrm{NaCl}$ in $1 \mathrm{~L}$ of deionized water. Then, the glass container was placed in an oven (Gravity Convection Oven, Economy Model, 18EG) to control the temperature at either 25 or $80{ }^{\circ} \mathrm{C}$ for a predetermined period. After the treatment, the membrane coupons were taken out from the container, dried at room temperature and subjected to contact angle and LEP measurement. The WCA of a coupon was measured at 20 spots, randomly chosen, by the scissel method using the VCA Optima Surface Analysis System (AST Product, Inc. Billerica, MA) with a drop size of $1 \mu \mathrm{L}$. The average values of WCA are reported. The WCA of the two fresh membranes without treatment was also measured.

LEP was measured using a static filtration cell shown schematically in Fig. 2. The cell is composed of a cylindrical chamber with a volume of $300 \mathrm{~mL}$. A membrane coupon was mounted on a porous metal plate embedded at the bottom of the cylindrical chamber and connected to the liquid outlet. For LEP measurement, water was loaded into the cylindrical chamber, and nitrogen pressure was applied. The pressure was gradually increased with a 2 psi interval, staying at each pressure for 10 minutes. The pressure at which the first droplet comes out from the outlet is recorded as LEP. The experiments were carried under the treatment conditions listed in Table 1. 


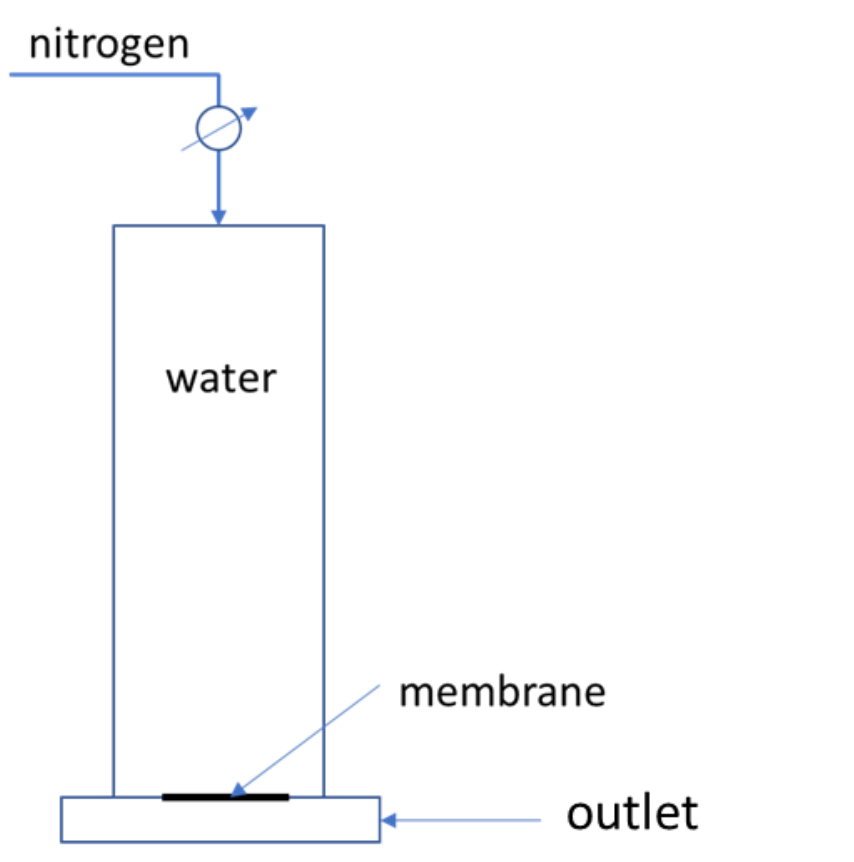

Fig. 2. LEP measurement setup.

Table 1. The treatment conditions.

\begin{tabular}{lll}
\hline Code of the experiment & Temperature, ${ }^{\circ} \mathrm{C}$ & Immersed in \\
\hline A & 25 & Deionized water \\
B & 25 & Artificial seawater \\
C & 80 & Deionized water \\
D & 80 & Artificial seawater \\
F & Without treatment & \\
\hline
\end{tabular}

\section{Results and discussion}

The average WCA values obtained by our study are shown in Fig. 3 as a function of immersion time, where week 0 refers to the fresh membrane (F) without being immersed in liquid. Standard deviations are also shown in Table 2. 


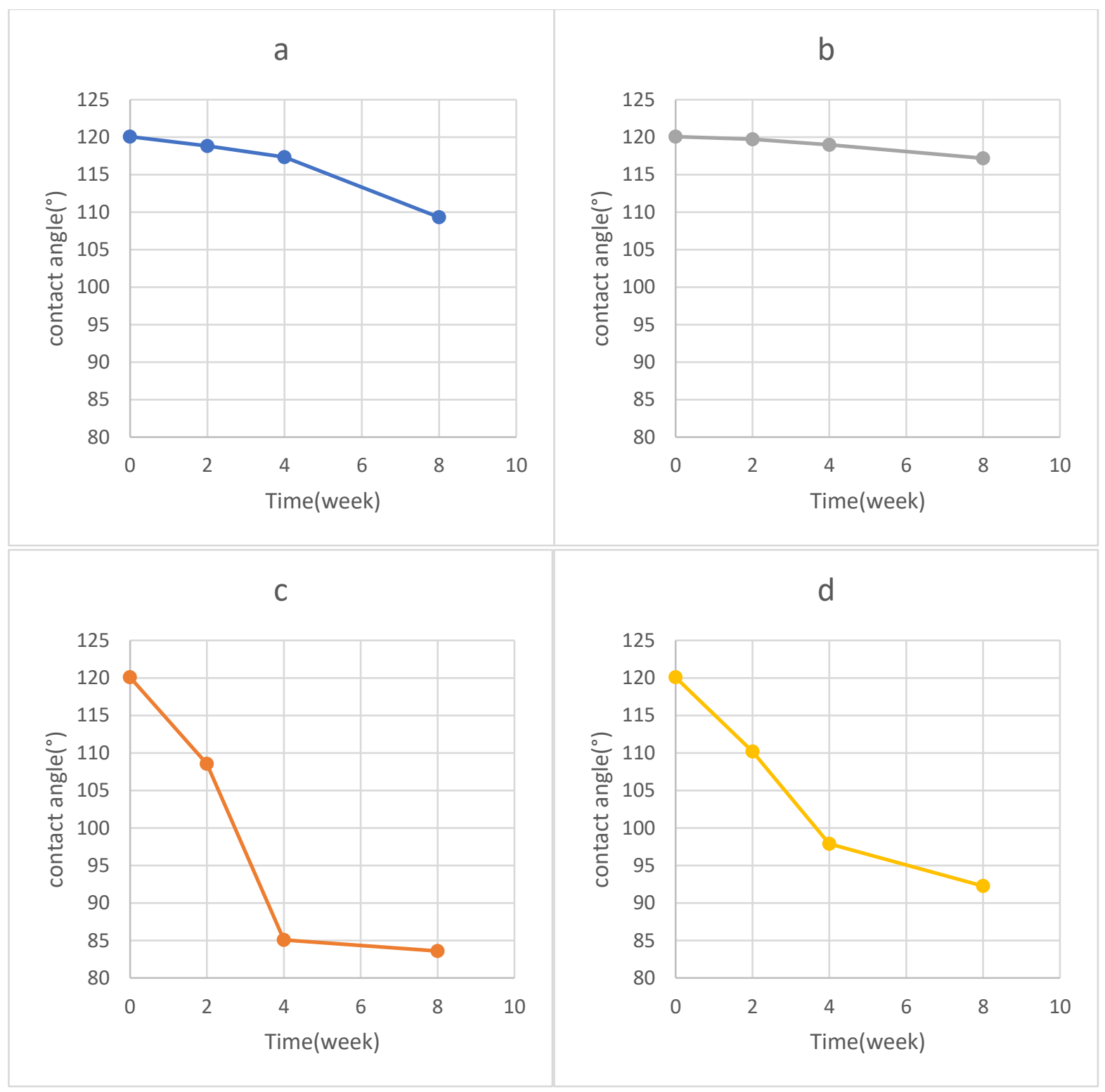

Fig. 3. WCA change with immersion time: (a) deionized water, $25^{\circ} \mathrm{C}$, (b) artificial seawater, $25^{\circ} \mathrm{C}$, (c) deionized water, $80^{\circ} \mathrm{C}$, and (d) artificial seawater, $80^{\circ} \mathrm{C}$. 
Table 2. WCA standard deviation of each data point in Fig. 3.

\begin{tabular}{lllll}
\hline \multicolumn{5}{l}{ WCA standard deviation $\left(^{\circ}\right)$} \\
Immersion time (week) & A & B & C & D \\
\hline 0 & 5.18 & 5.18 & 5.18 & 5.18 \\
2 & 10.31 & 13.77 & 7.46 & 12.89 \\
4 & 10.13 & 8.42 & 11.92 & 16.88 \\
8 & 12.73 & 12.86 & 11.89 & 9.41 \\
\hline
\end{tabular}

In accordance with Fig. 3, WCA of each group decreases with the immersion time, especially for groups $C$ and $\mathrm{D}$, where the coupons were treated at $80^{\circ} \mathrm{C}$. Due to the significant variation of the WCA data within a group, indicated by the relatively large standard deviations, T-test (Two-tails, unpaired with equal variance) was carried out using the data points at eight weeks of each group (A to D) as well as fresh membrane (F), and the results are shown in Table 3 as |t stat| (absolute value of $\mathrm{t}$ ). It should be noted that two membrane coupons were used for each group, including fresh membrane (F). Therefore, to know the variation between the coupons, T-test was also carried out between the two F coupons. Thus, in Table 3, F-F means the T-test with the null hypothesis that the WCA data from 2 coupons taken from the fresh membrane are from the same population. With a degree of freedom of 18 (20 randomly chosen spots -2 ) the negative $t$ critical value is -2.02 . Therefore, if the observed |t stat| is more than 2.02 , the null hypothesis is rejected with $95 \%$ probability.

Table 3. T-test from two-tails, unpaired with equal variance for different groups.

\begin{tabular}{llllllllll}
\hline & F-F & F-A & F-B & F-C & F-D & A-B & C-D & A-C & B-D \\
\hline |t stat & 2.26 & 3.43 & 0.96 & 12.47 & 11.09 & 1.87 & 2.62 & 6.49 & 6.68 \\
\hline
\end{tabular}

From the table, |t stat | can be classified into three categories:

1. $\mid$ t stat $\mid<2.02$ in which F-B and A-B are included;

2. $\mid$ t stat $\mid=2-4 \geq 2.02$ in which F-F, F-A and C-D are included;

3. $\mid$ t stat $\mid>6>2.02$ in which F-C, F-D, A-C and B-D are included.

Class 1 indicates clearly that the null-hypothesis that the means of two groups are from the same population is satisfied. It means that there is no difference between the two groups. 
Class 2 indicates that the null-hypothesis is rejected. Therefore, the means of two groups are from different populations. Yet, the difference of the means is small.

Class 3 Indicates clearly that the null-hypothesis is rejected. The means of the two groups are from different populations. Besides, the difference of the means is very large.

Therefore, the following statistical conclusion can be drawn:

- There is no change in the membrane WCA when F is treated at room temperature in seawater. The effect of treatment at room temperature does not depend on whether the treatment is with deionized water or seawater.

- WCA changes slightly when $\mathrm{F}$ is treated at room temperature in deionized water. There is also a slight difference in membrane WCA depending on whether the $80^{\circ} \mathrm{C}$ treatment is in deionized water or seawater. But these changes are comparable to the change between two coupons of the fresh membrane.

- Finally, the WCA of $\mathrm{F}$ has changed significantly at $80^{\circ} \mathrm{C}$ treatment either in deionized water or seawater. There is also a significant difference between $80^{\circ} \mathrm{C}$ and room temperature treatment.

Overall, it can be concluded that there is a significant decrease in WCA when the fresh membrane is treated at $80^{\circ} \mathrm{C}$. But the difference between the treatment in deionized water and seawater is statistically insignificant.

Regarding LEP measurement, LEP of the fresh membrane without treatment was 52 psi. LEPs of the membranes after eight weeks of treatment decreased slightly from that of the fresh membrane, but the change was below 4 psi.

Despite the large decrease in WCA, the decrease in LEP seems rather insignificant, which indicates that the WCA measured with a water droplet of $1 \mu \mathrm{L}$, covering an area with a radius of few $\mathrm{mm}$, cannot necessarily be used to evaluate the LEP of the pore whose size $(0.1 \mu \mathrm{m})$ is orders of magnitude smaller than that of the water droplet.

\section{Conclusions}

WCA, as well as LEP, were obtained experimentally to study the change in the pore wetting properties of a commercial PVDF hydrophobic membrane during eight weeks of immersion in either deionized water or artificial seawater at different temperatures. A small but statistically significant difference in the contact angles was observed between two coupons taken from a fresh commercial membrane without immersion. WCA change was either insignificant (in seawater) or equivalent to the difference from coupon to coupon (in deionized water) when it was treated at room temperature. The change was very significant when the coupons were treated at $80^{\circ} \mathrm{C}$, but the difference between deionized water and seawater was equivalent to the difference between coupon and coupon. LEP decreased slightly by the treatment, but the change was not as large as that of WCA.

K. Jiang et al. /Journal of Construction Materials | Special Issue 2021 


\section{Acknowledgment}

The authors greatly acknowledge the support of NSERC individual discovery grant RGPIN-2014-03753.

\section{References}

[1] J. Luliano, A. Singh, and F. Sartipi, "Political-economical evaluation of CO2 capture in Australian building sector," Journal of Construction Materials, vol. 1, no. 3, 2020, doi: 10.36756/JCM.v1.3.2.

[2] F. Sartipi, "Automatic sorting of recycled aggregate using image processing and object detection," Journal of Construction Materials, vol. 1, no. 3, 2020, doi: 10.36756/JCM.v1.3.3.

[3] A. Todhunter, M. Crowley, F. Sartipi, and K. Jegendran, "Use of the by-products of post-combustion carbon capture in concrete production: Australian case study," Journal of Construction Materials, vol. 1, no. 1, 2019.

[4] M. R. Abdali, Nima Mohamadian, H. Ghorbani, and D. A. Wood, "Petroleum Well Blowouts as a Threat to Drilling Operation and Wellbore Sustainability: Causes, Prevention, Safety and Emergency Response," Journal of Construction Materials, 2021, doi: 10.36756/JCM.si1.1r.

[5] F. A. Banat and J. Simandl, "Desalination by Membrane Distillation: A Parametric Study," Separation Science and Technology, vol. 33, no. 2, pp. 201-226, 1998, doi: 10.1080/01496399808544764.

[6] A. Alkhudhiri, N. Darwish, and N. Hilal, "Membrane distillation: A comprehensive review," Desalination, vol. 287, pp. 2-18, 2012, doi: 10.1016/j.desal.2011.08.027.

[7] J. Blanco Gálvez, L. García-Rodríguez, and I. Martín-Mateos, "Seawater desalination by an innovative solar-powered membrane distillation system: the MEDESOL project," Desalination, vol. 246, no. 1-3, pp. 567-576, 2009, doi: 10.1016/j.desal.2008.12.005.

[8] G. Zakrzewska-Trznadel, M. Harasimowicz, and A. G. Chmielewski, "Concentration of radioactive components in liquid low-level radioactive waste by membrane distillation," Journal of Membrane Science, vol. 163, no. 2, pp. 257-264, 1999, doi: 10.1016/S0376-7388(99)00171-4.

[9] P. P. Zolotarev, V. V. Ugrozov, I. B. Volkina, and V. M. Nikulin, "Treatment of waste water for removing heavy metals by membrane distillation," Journal of Hazardous Materials, vol. 37, no. 1, pp. 7782, 1994, doi: 10.1016/0304-3894(94)85035-6.

[10] M. Gryta, M. Tomaszewska, and K. Karakulski, "Wastewater treatment by membrane distillation," Desalination, vol. 198, no. 1-3, pp. 67-73, 2006, doi: 10.1016/j.desal.2006.09.010.

[11] M. C. García-Payo, C. A. Rivier, I. W. Marison, and U. Von Stockar, "Separation of binary mixtures by thermostatic sweeping gas membrane distillation II. Experimental results with aqueous formic acid solutions," Journal of Membrane Science, vol. 198, no. 2, pp. 197-210, 2002, doi: 10.1016/S03767388(01)00649-4.

[12] K. W. Lawson and D. R. Lloyd, "Membrane distillation," Journal of Membrane Science, vol. 124, no. 1, pp. 1-25, 1997, doi: 10.1016/S0376-7388(96)00236-0. 
[13] M. S. El-Bourawi, Z. Ding, R. Ma, and M. Khayet, "A framework for better understanding membrane distillation separation process," Journal of Membrane Science, vol. 285, no. 1-2, pp. 4-29, 2006, doi: 10.1016/j.memsci.2006.08.002.

[14] F. Laganà, G. Barbieri, and E. Drioli, "Direct contact membrane distillation: Modelling and concentration experiments," Journal of Membrane Science, vol. 166, no. 1, pp. 1-11, 2000, doi: 10.1016/S0376-7388(99)00234-3.

[15] H. Chamani, T. Matsuura, D. Rana, and C. Q. Lan, "Transport characteristics of liquid-gas interface in a capillary membrane pore," Journal of Membrane Science, vol. 611, 118387, 2020, doi: 10.1016/j.memsci.2020.118387.

[16] M. Khayet and T. Matsuura, "Preparation and characterization of polyvinylidene fluoride membranes for membrane distillation," Industrial \& Engineering Chemistry Research, vol. 40, no. 24, pp. 5710-5718, 2001, doi: 10.1021/ie010553y.

[17] N. M. Mahmoodi, Z. Mokhtari-Shourijeh, S. Langari, A. Naeimi, B. Hayati, M. Jalili, and K. Seifpanahi-Shabani, "Silica aerogel/polyacrylonitrile/polyvinylidene fluoride nanofiber and its ability for treatment of colored wastewater," Journal of Molecular Structure, vol. 1227, 129418, 2021, doi: 10.1016/j.molstruc.2020.129418.

[18] H. Chamani, P. Yazgan-Birgi, T. Matsuura, D. Rana, M. I. Hassan Ali, H. A. Arafat, and C. Q. Lan, "CFDbased genetic programming model for liquid entry pressure estimation of hydrophobic membranes," Desalination, vol. 476, 114231, 2020, doi: 10.1016/j.desal.2019.114231.

[19] Y. Chen, Z. Wang, G. K. Jennings, and S. Lin, "Probing pore wetting in membrane distillation using impedance: Early detection and mechanism of surfactant-induced wetting," Environmental Science \& Technology Letters, vol. 4, no. 11, pp. 505-510, 2017, doi: 10.1021/acs.estlett.7b00372.

[20] J. Zhang, N. Dow, M. Duke, E. Ostarcevic, J. De Li, and S. Gray, "Identification of material and physical features of membrane distillation membranes for high performance desalination," Journal of Membrane Science, vol. 349, no. 1-2, pp. 295-303, 2010, doi: 10.1016/j.memsci.2009.11.056.

[21] L. Eykens, K. De Sitter, C. Dotremont, L. Pinoy, and B. Van der Bruggen, "Membrane synthesis for membrane distillation: A review," Separation and Purification Technology, vol. 182, pp. 36-51, 2017, doi: 10.1016/j.seppur.2017.03.035.

[22] L. Eykens, K. De Sitter, C. Dotremont, L. Pinoy, and B. Van Der Bruggen, "How to Optimize the Membrane Properties for Membrane Distillation: A Review," Industrial \& Engineering Chemistry Research, vol. 55, no. 35, pp. 9333-9343, 2016, doi: 10.1021/acs.iecr.6b02226.

[23] H. Chamani, T. Matsuura, D. Rana, and C. Q. Lan, "Modeling of pore wetting in vacuum membrane distillation," Journal of Membrane Science, vol. 572, pp. 332-342, 2019, doi: 10.1016/j.memsci.2018.11.018.

[24] E. Guillen-Burrieza, M. O. Mavukkandy, M. R. Bilad, and H. A. Arafat, "Understanding wetting phenomena in membrane distillation and how operational parameters can affect it," Journal of Membrane Science, vol. 515, pp. 163-174, 2016, doi: 10.1016/j.memsci.2016.05.051.

K. Jiang et al. /Journal of Construction Materials | Special Issue 2021 
[25] M. Rezaei, D. M. Warsinger, J. H. Lienhard V, M. C. Duke, T. Matsuura, and W. M. Samhaber, "Wetting phenomena in membrane distillation: Mechanisms, reversal, and prevention," Water Research, vol. 139, pp. 329-352, 2018, doi: 10.1016/j.watres.2018.03.058.

[26] R. B. Saffarini, B. Mansoor, R. Thomas, and H. A. Arafat, "Effect of temperature-dependent microstructure evolution on pore wetting in PTFE membranes under membrane distillation conditions," Journal of Membrane Science, vol. 429, pp. 282-294, 2013, doi: 10.1016/j.memsci.2012.11.049. 